\title{
Role of ineffective erythropoiesis in the anaemia of rheumatoid arthritis
}

\author{
DIANA SAMSON, D. HALLIDAY, AND J. M. GUMPEL \\ From the Department of Haematology, Division of Clinical Investigation and Rheumatic Diseases \\ Study Group, Northwick Park Hospital and Clinical Research Centre, Watford Road, Harrow, \\ Middlesex HAI 3 UJ
}

SUMMARY The importance of inadequate haemoglobin synthesis and ineffective erythropoiesis in the anaemia of rheumatoid arthritis was studied by measuring the incorporation of ${ }^{15} \mathrm{~N}$ glycine into haemoglobin haem and early labelled bilirubin in a patient with severe anaemia before and after response to gold therapy. Initially, total erythroid haem turnover was decreased but haem turnover due to ineffective erythropoiesis was markedly increased, accounting for $29 \%$ of total erythroid haem turnover. Gold therapy resulted in marked clinical improvement, accompanied by a rise in haemoglobin to normal. Total erythroid haem turnover increased and the percentage ineffective erythropoiesis fell to normal. Ineffective erythropoiesis may thus be an important reversible factor in the produc.ion of the anaemia of rheumatoid arthritis.

Anaemia is frequently present in patients with active rheumatoid arthritis (Jeffrey, 1953; Freireich et al., 1957; Roberts et al., 1963; Mowat, 1971). In common with the anaemia of other chronic disorders it is characterized by a low serum iron and a low total iron-binding capacity with normal or increased reticuloendothelial iron stores. It is usually normocytic and normochromic but microcytosis or hypochromia may also be seen, either singly or in association (Cartwright, 1966). The mean cell life is usually slightly shortened; there is rapid clearance of iron from the plasma but incorporation of exogenous ${ }^{59} \mathrm{Fe}$ transferrin into red cells is normal or only slightly reduced (Freireich et al., 1957; Weinstein, 1959; Roberts et al., 1963). It is therefore thought that the anaemia results from failure of red cell production rate to increase to compensate for the slight increase in the rate of destruction. Although ${ }^{59} \mathrm{Fe}$ bound to transferrin is incorporated reasonably well into red cells, endogenous iron, derived from red cells labelled with ${ }^{59} \mathrm{Fe}$ or from ${ }^{59} \mathrm{Fe}$ dextran, is poorly utilized. Impaired release of iron from the reticuloendothelial system is therefore thought to be the major cause of the inadequate haemoglobin synthesis (Weinstein, 1959; Haurani et al., 1965; Lawson et al., 1967; Beamish et al., 1971; Bennett et al., 1974). Failure of erythropoietin production may be an additional factor (Cartwright, 1966).

Accepted for publication June 30, 1976

Correspondence to Dr. J. M. Gumpel
Ineffective erythropoiesis has not been considered a feature of the anaemia of chronic disorders, although morphological evidence of dyserythropoiesis is commonly seen in the bone marrow. We therefore undertook a quantitative study of ineffective and effective haem synthesis in a patient with classical anaemia of rheumatoid arthritis by measuring total bilirubin turnover rate and the incorporation of ${ }^{15} \mathrm{~N}$ glycine and ${ }^{15} \mathrm{~N} \delta$-aminolaevulinic acid (ALA) into haemoglobin and early labelled bilirubin. After administration of ${ }^{15} \mathrm{~N}$ glycine and its incorporation into haem, labelled red cells appear in the circulation reaching a plateau at about 10 days. Their subsequent destruction gives rise to a peak of labelled bile pigment excretion at the end of the mean cell life span. A peak of labelled bile pigment production also occurs during the first 10 days after ${ }^{15} \mathrm{~N}$ glycine administration, which in normal subjects accounts for $10-20 \%$ of total labelled pigment production. This early labelled peak arises partly from intramedullary cell death, i.e. ineffective erythropoiesis, but some early labelled bile pigment also arises from the breakdown of hepatic haem proteins so that the contribution of the hepatic component of the early peak must be assessed in order to quantitate ineffective erythropoiesis. In contrast to glycine, exogenous ALA which is the successor of glycine in the haem synthetic pathway, is incorporated almost exclusively into hepatic haem (Berlin et al., 1969). The early labelled bilirubin peak resulting from the administration of ${ }^{15} \mathrm{~N}$ ALA can therefore be used to 
calculate hepatic haem turnover and hence the hepatic contribution to the early labelled peak resulting from ${ }^{15} \mathrm{~N}$ glycine administration. Using the clearance of ${ }^{14} \mathrm{C}$ bilirubin to measure total haem turnover rate, the rates of haem turnover due to effective erythropoiesis and ineffective erythropoiesis can then be calculated, as previously described (Samson et al., 1976a).

\section{Case report}

A woman, born in 1909, has had mild psoriasis for many years, and in 1964 developed a widespread symmetrical polyarthritis, diagnosed as rheumatoid arthritis on the basis of a repeatedly positive sheep cell agglutination test (titre of $1: 256$ ). In January 1971 there was a flare-up of the disease and in July 1971 the haemoglobin was $10.5 \mathrm{~g} / \mathrm{dl}$ and the erythrocyte sedimentation rate (ESR) $56 \mathrm{~mm} / \mathrm{h}$; subsequent levels are shown in Table 1. Radiographs showed extensive symmetrical erosive disease. She was first seen at Northwick Park Hospital in August 1971 , at which time she was taking phenylbutazone $100 \mathrm{mg}$ tds, dihydrocodeine $60 \mathrm{mg}$, and Distalgesic. She had also been taking oral iron for a year, which was then stopped. In December 1971 Hoffman's operation was performed on both feet and she had a further 3 months' course of iron, after which no more iron therapy was given. In February $19725 \mathrm{mCi}$ yttrium 90 was injected into each knee, and in June
1972 an ulnar head resection and synovectomy of the right wrist was performed, and benorylate wạs substituted for phenylbutazone.

In September 1972 there had been no response? the yttrium injections; in view of this, the widespreid erosive joint disease, the high ESR, and the anaenfia, she was judged to have sufficient generalized actwe rheumatoid arthritis to merit chrysotherapy. glycine studies were carried out at this time, and subsequently gold therapy was started. After $1210 \mathrm{mg}$ myocrisin there was marked clinical improvement; all manifestations of active rheumatoid arthritis häd disappeared and the gold was continued at 50 㽞g fortnightly as the only medication. In February 198 the interval between injections was increased toj 4 weeks and in December 1975 to 6 weeks. At this time a total dose of $2710 \mathrm{mg}$ had been given with no side effects. At no time during the course of her disease was there any abnormality in liver function tests. ?

Before starting gold therapy she had a persistent normochromic microcytic anaemia which had responded to oral iron (see Table 1). No evidence of blood loss from the gut was found and there was $\overrightarrow{00}$ postmenopausal bleeding. The anaemia was associated with a markedly raised ESR, a low serum irom, and a low normal total iron binding capacity. Bohe marrow aspiration showed adequate reticuifoendothelial iron stores and normoblastic erythmopoiesis with morphological evidence of dyserythmo-

Table 1 Haematology parameters in relation to therapy in patient

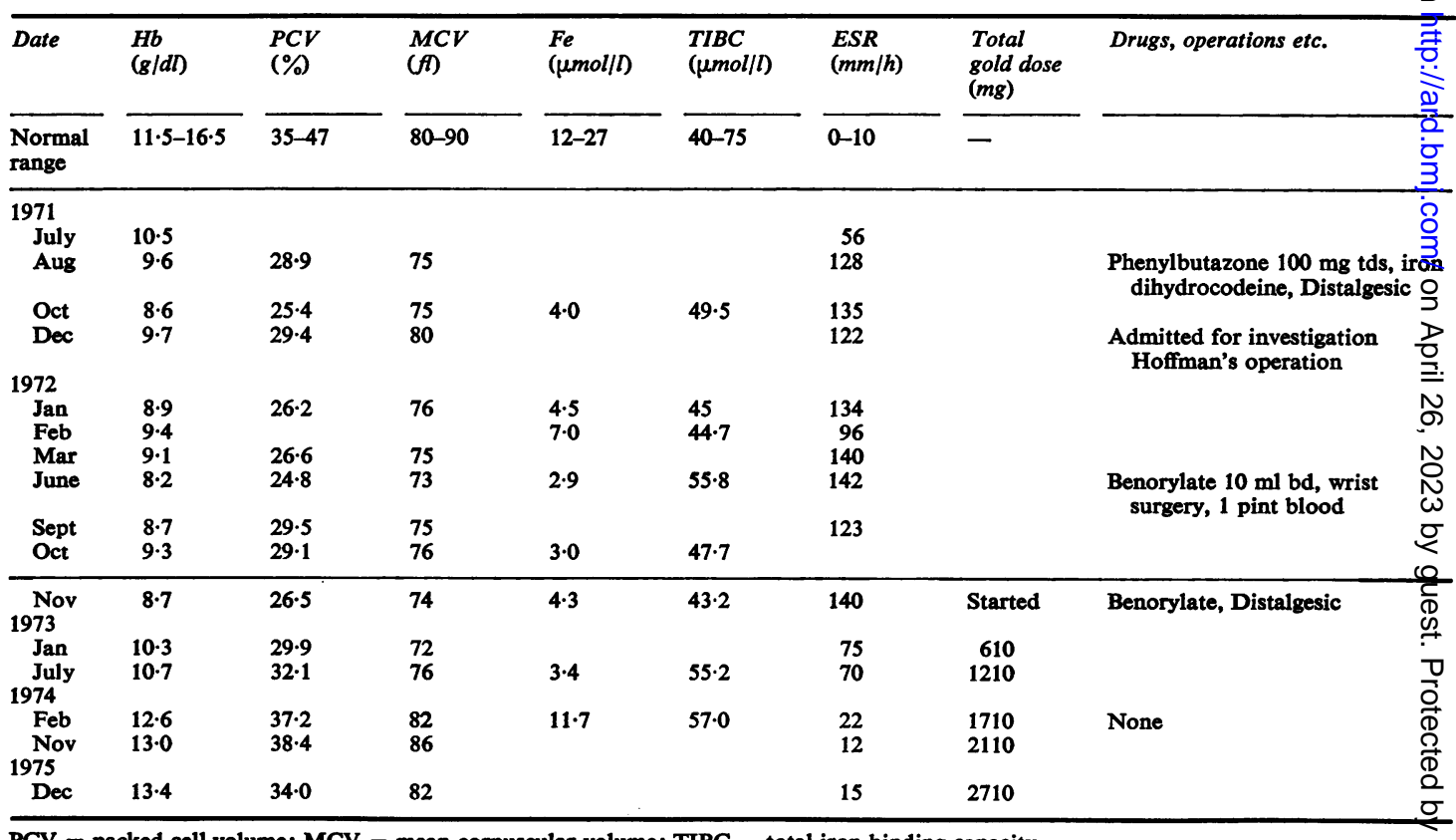

PCV = packed cell volume; $\mathrm{MCV}=$ mean corpuscular volume; $\mathrm{TIBC}=$ total iron binding capacity. 
poiesis, i.e. ragged cytoplasm, indistinct nuclear outline, and karyorrhexis. Ferrokinetic studies showed a rapid plasma iron clearance $\left(\mathrm{T}_{\frac{1}{2}}{ }^{59} \mathrm{Fe}\right.$ $55 \mathrm{~min}$, normal range 60-140) and reduced incorporation into circulating red cells $(43 \%$ utilization on day 14, normal range 70-80). 6 months after starting gold therapy there was some improvement of the haemoglobin and ESR, and after 18 months these had returned to normal. Serum iron rose spontaneously to normal and there was also a slight increase in total iron binding capacity (Table 1).

\section{Methods}

These have been described in full elsewhere (Samson et al., 1976a). The patient was admitted to a metabolic ward for a 20-day study period immediately before gold therapy. On day $0,20 \mathrm{mg}{ }^{15} \mathrm{~N}$ ALA was given by rapid intravenous injection, and on day 10 , when the early peak resulting from ALA administration was over, $50 \mathrm{mg}{ }^{15} \mathrm{~N}$ glycine was given by rapid intravenous injection. Stercobilin was isolated from individual stool samples by the method of Watson (1934) as modified by Gray and Scott (1959). Blood samples were taken three times weekly and haemin isolated by the method of Labbe and Nishida (1957). The atom percent excess ${ }^{15} \mathrm{~N}$ in the stercobilin and haemin samples was determined in an MS20 mass spectrometer. The total daily bilirubin production rate was determined by the clearance of ${ }^{14} \mathrm{C}$ bilirubin, and from this and the atom percent excess ${ }^{15} \mathrm{~N}$ of the stercobilin the percentage incorporation of both precursors into bilirubin over the 10-day period was calculated (see Table 2). Similarly, from the ${ }^{15} \mathrm{~N}$ concentration of the haemin and the total red cell mass, measured with ${ }^{51} \mathrm{Cr}$, the percentage incorporation of glycine into haemoglobin haem was calculated (Table 2). In October 1974, after 2 years of gold therapy, the total bilirubin turnover rate and the incorporation of ${ }^{15} \mathrm{~N}$ glycine into haemoglobin haem were again measured. The patient gave informed consent to the studies, which had been approved by Northwick Park Hospital Ethical Committee and the MRC Isotope Advisory Panel.

\section{CALCULATIONS}

Initial study

Total bilirubin turnover rate (BRT), bilirubin production from hepatic haem turnover ( $\left.B R_{H E P}\right)$, from ineffective erythropoiesis $\left(B R_{I E}\right)$, and from the destruction of circulating red cells $\left(B R_{R B C}\right)$, and the percentage ineffective erythropoiesis were calculated from the total haem turnover rate (bilirubin production rate) and the isotope incorporation as previously described (Samson et al., 1976a). The potential haemoglobin, i.e. that which would have been achieved at the same total erythroid haem turnover rate if there had been no increase in ineffective erythropoiesis, was also calculated (Samson et al., 1976b). Haem turnover rates are obtained by converting bilirubin production rates to molar units.

\section{Repeat study}

Let $\mathrm{BRT}_{2}, \mathrm{BR}_{\mathrm{IE}_{2}}$, and $\mathrm{BR}_{\mathrm{RBC}_{2}}$ be the new values for $B R T_{1}, B_{I E}$, and $B_{R_{B C}}$ and $G_{R_{B C}}$ be the incorporation of ${ }^{15} \mathrm{~N}$ glycine into haemoglobin haem on this occasion, where $G_{R_{B C}}$ was the incorporation into haemoglobin haem in the initial study. Assuming that the incorporation of ${ }^{15} \mathrm{~N}$ glycine into haemoglobin haem is proportional to the rate of effective haem synthesis,

$$
\begin{aligned}
& \frac{\mathrm{G}_{\mathrm{RBC}_{2}}}{\overline{B R}_{\mathrm{RBC}_{2}}}=\frac{\mathrm{G}_{\mathrm{RBC}_{1}}}{\mathrm{BR}_{\mathrm{RBC}_{1}}} \\
& \underline{\mathrm{BR}_{\mathrm{RBC}_{2}}}=\frac{\mathrm{BR}_{\mathrm{RBC}_{1}} \times \mathrm{G}_{\mathrm{RBC}_{2}}}{\mathrm{G}_{\mathrm{RBC}_{1}}}
\end{aligned}
$$

Further, assuming hepatic haem turnover to have remained constant,

$$
\begin{aligned}
& \quad \mathrm{BR}_{\mathrm{IE}_{2}}=\mathrm{BRT}_{2}-\mathrm{BR}_{\mathrm{RBC}_{2}}-\mathrm{BR}_{\mathrm{HEP}} \\
& \text { and \% ineffective erythropoiesis }=\mathrm{BR}_{\mathrm{IE}_{2}} / \mathrm{BR}_{\mathrm{IE}_{2}} \\
& +\mathrm{BR}_{\mathrm{RBC}_{2}} \text {. }
\end{aligned}
$$

\section{Results}

\begin{tabular}{|c|c|c|c|c|}
\hline Precursor & Product & Normal range* & $\begin{array}{l}\text { Patient before } \\
\text { gold therapy }\end{array}$ & $\begin{array}{l}\text { Patient after } \\
\text { gold therapy }\end{array}$ \\
\hline $\begin{array}{l}\text { Glycine } \\
\text { Glycine }\end{array}$ & $\begin{array}{l}\text { Hb haem } \\
\text { Early labelled } \\
\text { bilirubin }\end{array}$ & $\begin{array}{l}1.24 \pm 0.24 \\
0.23 \pm 0.06\end{array}$ & $\begin{array}{l}0.56 \\
0.37\end{array}$ & $\begin{array}{l}0.95 \\
-\end{array}$ \\
\hline ALA & $\begin{array}{l}\text { Early labelled } \\
\text { bilirubin }\end{array}$ & $18 \cdot 40 \pm 7 \cdot 77$ & $22 \cdot 20$ & - \\
\hline
\end{tabular}

Initially the incorporation of ${ }^{15} \mathrm{~N}$ glycine into haemoglobin haem was markedly reduced, but the incorporation into early labelled bilirubin was

Table 2 Incorporation of ${ }^{15} N A L A$ and ${ }^{15} N$ glycine into haem and early labelled bilirubin (\% administered dose)

*Samson et al. (1976a). 
increased (Table 2). The incorporation of ${ }^{15} \mathrm{~N}$ ALA into early labelled bilirubin was normal, indicating that hepatic haem turnover was within the normal range $(1.56 \mu \mathrm{mol} / \mathrm{kg}$ per day, mean $\pm \mathrm{SD} 1.30 \pm$ 0.55 ). The increased incorporation of ${ }^{15} \mathrm{~N}$ glycine into the early labelled peak was therefore due to increased ineffective erythropoiesis,

Total haem turnover, measured by the clearance of ${ }^{14} \mathrm{C}$ bilirubin, was reduced $(5.96 \mu \mathrm{mol} / \mathrm{kg}$ per day, mean \pm SD 6.75 \pm 0.46 ) (see Fig.) and since hepatic haem turnover was normal, this was due to a decreased total erythroid haem turnover $(4.40 \mu \mathrm{mol} /$ $\mathrm{kg}$ per day, mean \pm SD $5.46 \pm 0.50$ ). Because of the increased percentage ineffective erythropoiesis $(29 \%$, mean $\pm S D ~ 8 \pm 3$ ) the rate of effective haem synthesis was considerably reduced $(3 \cdot 13 \mu \mathrm{mol} / \mathrm{kg}$ per day, mean \pm SD $5.03 \pm 0.51$ ) and the haem turnover rate due to ineffective erythropoiesis was actually increased $(1.27 \mu \mathrm{mol} / \mathrm{kg}$ per day, mean \pm SD $0.45 \pm 0.17$ ). The potential haemoglobin, i.e. that which would have been achieved at the same level of total erythroid haem turnover if the percentage ineffective erythropoiesis had been normal, was $11 \cdot 3 \mathrm{~g} / \mathrm{dl}$.

When studied after gold therapy, total haem turnover had risen to normal $(7.35 \mu \mathrm{mol} / \mathrm{kg}$ per day). Assuming hepatic haem turnover to have remained constant, this indicated a rise in total erythroid haem turnover to $5.78 \mu \mathrm{mol} / \mathrm{kg}$ per day. According

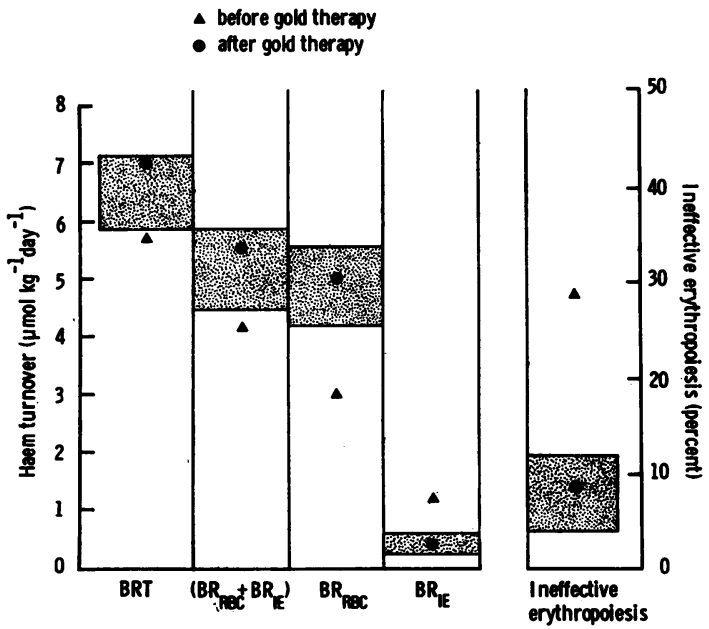

Fig. Haem turnover and ineffective erythropoiesis before and after gold therapy in the patient studied. BRT is total haem turnover rate (total bilirubin turnover rate). $B R_{R B C}$ and $B R_{I E}$ are haem turnover rates due respectively to effective and ineffective erythropoiesis, and $\left(B R_{R B C}+\right.$ $\left.B R_{I E}\right)$ is total erythroid haem turnover rate. The shaded area shows the range of values in 4 control subjects (Samson et al., 1976a). to the above calculations, effective haem turnover was now $5 \cdot 29 \mu \mathrm{mol} / \mathrm{kg}$ per day, so that ineffect $\bar{p}$. haem turnover was $0.49 \mu \mathrm{mol} / \mathrm{kg}$ per day, i.e. $10 \mathrm{~J}_{\%}^{\circ}$ of total erythroid haem turnover. Although there may be a small error in this estimate owing to the assumption of a constant value for hepatic hasesh turnover, the difference from the pretreatment valife is too great to be accounted for by a variation on hepatic haem turnover rate. In view of the consistently normal liver function tests, there was $\overrightarrow{0}$ evidence that liver function had altered between the two periods of study.

\section{Discussion}

Before gold therapy the patient had a moderatepy severe anaemia associated with active generalized rheumatoid arthritis. The slight microcytosis, law serum iron and iron binding capacity with adequate marrow iron stores were all characteristic of the anaemia of chronic disorders. At this time to erythroid haem turnover was marginally reduced (see Fig.), consistent with failure of iron utilization and/or insufficient erythropoietin production. Ineffective erythropoiesis accounted for $29 \%$ of togal erythroid haem turnover, so that effective haen turnover was considerably reduced. In the absence ${ }^{\circ}$ f an increase in ineffective erythropoiesis the haentsglobin would have been $11 \cdot 3 \mathrm{~g} / \mathrm{dl}$, which is appro\&imately halfway between the actual level $(8.7 \mathrm{~g} / \mathrm{di})$ and the expected normal level. Failure of haembglobin synthesis and ineffective erythropoiesis were therefore of equal importance in the production $\mathrm{f} f$ the anaemia in the present case. The low incorporattion of ${ }^{59} \mathrm{Fe}$ into red cells is consistent with this interpretation. Since ${ }^{59} \mathrm{Fe}$ incorporation is usuaty normal or only slightly reduced in the anaemia of rheumatoid arthritis the increase of ineffect pe erythropoiesis in the present case may be unusuahy high. Nevertheless it is likely that ineffective eryth 8 poiesis is a factor in the production of this type anaemia.

After successful treatment of the arthritis with gold, all the parameters returned to normal (see Tables 1, 2, Fig.). Both the failure of haemoglom synthesis and the ineffective erythropoiesis wepe therefore reversed by gold therapy.

\section{References}

Beamish. M. R., Davies, A. G., Eakins, J. D., Jacobs, ․․, and Trevett, D. (1971). The measurement of reticufoendothelial iron release using iron-dextran. British Joureal of Haematology, 21, 617-622.

Bennett, R. M., Holt, P. J. L., and Lewis, S. M. (1974). ROite of the reticuloendothelial system in the anaemia of rheunatoid arthritis. Annals of the Rheumatic Disesses, 33, 147-152. 
Berlin, N. I., Berk, P. D., and Howe, R. B. (1969). Disorders of bilirubin metabolism. Duncan's Diseases of Metabolism, 6th ed. Ed. by P. K. Bondy. Saunders, London.

Cartwright, G. E. (1966). The anemia of chronic disorders. Seminars in Hematology, 3, 351-375.

Freireich, E. J., Ross, J. F., Bayles, T. B., Emerson, C. P., and Finch, S. C. (1957). Radioactive iron metabolism and erythrocyte survival studies of the mechanism of the anemia associated with rheumatoid arthritis. Journal of Clinical Investigation, 36, 1043-1058.

Gray, C. H., and Scott, J. J. (1959). The effect of hemorrhage on the incorporation of a $-{ }^{14} \mathrm{C}$ glycine into stercobilin. Biochemical Journal, 71, 38-42.

Haurani, F. I., Burke, W., and Martinez, E. J. (1965). Defective re-utilization of iron in the anemia of inflammation. Journal of Laboratory and Clinical Medicine, 65, 560-570.

Jeffrey, M. R. (1953). Some observations on anemia in rheumatoid arthritis. Blood, 8, 502-518.

Labbe, R. F., and Nishida, G. (1957). A new method of haemin isolation. Biochimica et Biophysica Acta, 26, 437.

Lawson, A. A. H., Owen, E. T., and Mowat, A. G. (1967). Nature of anaemia in rheumatoid arthritis. VII. Storage of iron in rheumatoid disease. Annals of the Rheumatic Diseases, 26, 552-559.

Mowat, A. G. (1971). Hematologic abnormalities in rheumatoid arthritis. Seminars in Arthritis and Rheumatism, 1, 195-219.

Roberts, F. D., Hagedorn, A. B., Slocumb, C. H., and Owen, C. A. (1963). Evaluation of the anemia of rheumatoid arthritis. Blood, 21, 470-476.

Samson, D., Halliday, D., Nicholson, D. C., and Chanarin, I. (1976a). Quantitation of ineffective erythropoiesis from the incorporation of $\left({ }^{15} \mathrm{~N}\right) \delta$-amino-laevulinic acid and $\left({ }^{15} \mathrm{~N}\right)$ glycine into early labelled bilirubin. I. Normal subjects. British Journal of Haematology, 34, 33-34.

Samson, D., Halliday, D., Nicholson, D. C., and Chanarin, I. (1976b). Quantitation of ineffective erythropoiesis from the incorporation of $\left({ }^{15} \mathrm{~N}\right) \delta$-amino-laevulinic acid and $\left({ }^{15} \mathrm{~N}\right)$ glucine into early labelled bilirubin. II. Anaemic patients. British Journal of Haematology, 34, 45-53.

Watson, C. J. (1934). An improved method for the isolation of crystalline stercobilin. Journal of Biological Chemistry, 105, 469-472.

Weinstein, I. M. (1959). A correlative study of the erythrokinetics and disturbances in iron metabolism associated with the anemia of rheumatoid arthritis. Blood, 14, 950-966. 